\title{
Análisis de prensa de los casos de dopaje de Marta Domínguez y Alberto Contador: ¿héroes o villanos?
}

\author{
Rodrigo PARDO \\ Universidad Politécnica de Madrid \\ rodrigo.pardo@upm.es \\ Dominique Bodin \\ Universidad de Rennes 2 \\ dominique.bodin@univ-rennes2.fr
}

Recibido: 23 de junio de 2012.

Aceptado: 15 de julio de 2012.

\begin{abstract}
Resumen
Dos de los deportistas españoles más importantes, Alberto Contador (ciclista) y Marta Domínguez (atleta), estuvieron involucrados entre 2010 y 2012 en dos casos relacionados con el dopaje. Este texto analizará, de forma cualitativa y cuantitativa, el tratamiento que han recibido ambos casos por dos periódicos españoles (El Mundo y El País) y cómo estos deportistas han sido retratados por estos medios de comunicación de manera diferente en relación a cuestiones tales como la implicación económica, la política, la presunción de inocencia, su vida privada y el nacionalismo deportivo como consecuencia de la repercusión pública que ambos casos han tenido y la imagen internacional que se ha proyectado del deporte español.
\end{abstract}

Palabras clave: Dopaje; ciclismo; atletismo; medios de comunicación; prensa.

\section{Press analysis of Marta Domínguez and Alberto Contador doping cases: heroes or villains?}

\begin{abstract}
Alberto Contador (cyclist) and Marta Domínguez (athlete), two of the most relevant Spanish sportsmen, were involved since 2010 to 2012 in two cases related to doping. This text will analyze, using quantitative and qualitative techniques, the treatment that both cases have received by two Spanish newspapers (i.e., El Mundo and El País) and how these sportsmen have been different portrayed according to issues such as economics, politics, presumption of innocence, privacy and sport nationalism as consequence of the public impact that both cases have had in the international image portrayed by the Spanish sport.
\end{abstract}

Key words: Cycling; athletics; doping; media; newspaper.

\section{Referencia normalizada}

Pardo, R., Bodin, D. (2012). Análisis de prensa de los casos de dopaje de Marta Domínguez y Alberto Contador: ¿Héroes o villanos?. Historia y Comunicación Social, Vol. 17, páginas 297-316.

Sumario: 1. Introducción. 2. Los protagonistas. Alberto Contador y Marta Domínguez. 3. Cronología de dos casos. 4. Metodología. 5. Resultados. 6. Conclusiones. 7. Bibliografía. 


\section{Introducción}

A finales de 2010, dos casos de dopaje sacudieron el mundo del deporte en España. Dos de los deportistas españoles más relevantes en ese momento, Alberto Contador (ciclista) y Marta Domínguez (atleta), se vieron envueltos en dos casos relacionados con el dopaje. Los medios de comunicación recogieron esta noticia en todas sus portadas, jugando un papel clave en los meses siguientes al informar a la opinión pública acerca de lo acontecido en estos dos casos.

Los medios de comunicación tienen una gran influencia (y responsabilidad) en la perpetuación de ciertas ideologías (Duncan, 1993) y la manera en que retratan el dopaje en el deporte puede tener un enorme impacto en las personas. Hay numerosos ejemplos de análisis del deporte a través de los medios de comunicación, como por ejemplo los trabajos de Douglas (2002), Duncan (1990 y 1993), Hilliard (2005), Messner, Dunbar, y Hunt (2005), y Walton (2001), entre otros. Sin embargo, el presente análisis, debido a su actualidad, puede despertar cierto interés en este sentido.

El propósito de este trabajo es comparar la cobertura que dos periódicos españoles (El Mundo y El País) realizaron de estos dos casos con el fin de comprender mejor cómo los medios retratan a los deportistas que se ven involucrados en casos relacionados con el dopaje, teniendo en cuenta que ambos están en activo y tienen la misma nacionalidad que los periódicos elegidos para el análisis.

\section{Los protagonistas: Alberto Contador y Marta Domínguez}

Antes de comenzar con el análisis de prensa, es necesario explicar brevemente la carrera profesional de estos dos deportistas con el fin de entender mejor la conmoción que causó en la opinión pública española las acusaciones de dopaje, en el caso de Alberto Contador, y de tráfico de sustancias dopantes - entre otros cargos- en el caso de Marta Domínguez.

\subsection{Alberto Contador}

Alberto Contador comenzó su carrera profesional como ciclista en 2003. Apareció en la escena internacional en 2007 al ganar el Tour de Francia. Después de sus victorias en el Giro de Italia y la Vuelta a España, se convirtió en 2008 en el primer ciclista español en ganar las tres Grandes Vueltas. Su última victoria oficial fue en 2009, cuando ganó su segundo Tour de Francia. Además, ganó la Velo d'Or, premio concedido al mejor ciclista del año, de manera consecutiva en 2007, 2008 y 2009. Después de la resolución del Tribunal de Arbitraje Deportivo (TAS), fue descalificado de las victorias conseguidas en el Tour de Francia 2010 y en el Giro de Italia 2011. 


\subsection{Marta Domínguez}

Marta Domínguez es atleta profesional y compite principalmente en carreras de fondo y medio fondo. Está considerada como la mejor atleta española hasta la fecha y sus logros más relevantes son: en 2002 fue campeona de Europa en pista cubierta de 3.000 m.; en 2002 y 2006 fue campeona de Europa de 5.000 m.; en 2007 ganó el campeonato de Europa de campo a través; en 2009 ganó el campeonato del mundo en la modalidad de $3.000 \mathrm{~m}$. obstáculos; y en 2010, su último título, fue subcampeona de Europa en 3.000 m. obstáculos. En octubre de 2009 fue declarada mejor Atleta Europea del Año por la Asociación Europea de Atletismo y también ganó el galardón Reina Sofía de 2009, que premia a la deportista española que más se haya distinguido durante el año en su actuación deportiva, tanto en el ámbito nacional como internacional.

\section{Cronología de dos casos}

A continuación se destacan los acontecimientos más relevantes que han ocurrido durante el desarrollo de estos dos casos. Es necesario señalar que la naturaleza de ambos casos es diferente. Por un lado, el caso Contador se basa en el hallazgo de una sustancia dopante (clembuterol) en su sangre después de un control de dopaje durante el Tour de Francia 2010. Por otro lado, Domínguez se vio involucrada en una operación policial denominada Operación Galgo relacionada con el dopaje.

\subsection{Caso Contador}

La tabla 1 resume los principales acontecimientos relacionados con el caso Contador.

Tabla 1. Cronología del caso Contador.

\begin{tabular}{c|l}
\hline \multicolumn{1}{c|}{ Fecha } & \multicolumn{1}{|c}{ Acontecimiento } \\
\hline \hline $\begin{array}{c}\mathbf{2 0 1 0} \\
21 \text { julio }\end{array}$ & Durante el Tour de Francia realizan dos controles antidopaje a Contador. \\
\hline \hline 25 julio & Contador gana su tercer Tour de Francia. \\
\hline \hline 24 agosto & $\begin{array}{l}\text { La Unión Ciclista Internacional (UCI) le notifica que ha dado positivo por } \\
\text { clembuterol (50 picogramos) y que está suspendido cautelarmente. }\end{array}$ \\
\hline \hline 30 septiembre & $\begin{array}{l}\text { Contador hace público su positivo por dopaje pero declara su inocencia } \\
\text { argumentando que se debió a una contaminación alimentaria producida por la } \\
\text { ingesta de carne contaminada por clembuterol. }\end{array}$ \\
\hline \hline 8 noviembre & $\begin{array}{l}\text { La UCI propone a la Real Federación Española de Ciclismo (RFEC) abrir un } \\
\text { expediente disciplinario a Contador. }\end{array}$ \\
\hline \hline 26 enero & $\begin{array}{l}\text { La RFEC notifica a Contador la propuesta de un año de suspensión. Si ésta se } \\
\text { confirma, el corredor perdería su tercer Tour de Francia. }\end{array}$ \\
\hline \hline 7 febrero & $\begin{array}{l}\text { Contador alega no haber incurrido en negligencia y se declara inocente. La RFEC } \\
\text { debe decidir la sanción definitiva. }\end{array}$ \\
\hline \hline
\end{tabular}




\begin{tabular}{c|l}
\hline \hline 14 febrero & $\begin{array}{l}\text { La RFEC declara inocente a Contador argumentando que el corredor no ingirió de } \\
\text { manera voluntaria la sustancia dopante. }\end{array}$ \\
\hline \hline 24 marzo & $\begin{array}{l}\text { La UCI presenta alegaciones al TAS contra la resolución de la RFEC pidiendo la } \\
\text { suspensión de dos años y una multa equivalente a los ingresos netos obtenidos } \\
\text { durante un año. }\end{array}$ \\
\hline \hline 29 marzo & $\begin{array}{l}\text { La Agencia Mundial Antidopaje (AMA) también se persona en el TAS en los } \\
\text { mismos términos que la UCI. }\end{array}$ \\
\hline \hline 29 mayo & Contador gana el Giro de Italia. \\
\hline \hline $\begin{array}{c}\mathbf{2 0 1 2} \text { julio } \\
6 \text { febrero }\end{array}$ & Contador acaba en quinta posición en el Tour de Francia. \\
& $\begin{array}{l}\text { El TAS considera culpable a Contadory le condena a dos años de suspensión. Por } \\
\text { consiguiente, se le descalifica de las victorias obtenidas en el Tour de Francia 2010 } \\
\text { y el Giro de Italia 2011. No se le permite volver a la competición hasta el 12 de } \\
\text { agosto de 2012. }\end{array}$ \\
\hline \hline
\end{tabular}

Fuente: elaboración propia a partir de la información publicada en El Mundo y en El País.

\subsection{Caso Domínguez}

La tabla 2 resume los principales acontecimientos relacionados con la Operación Galgo y el caso Domínguez.

Tabla 2. Cronología de la Operación Galgo y del caso Domínguez.

\begin{tabular}{c|l}
\hline \multicolumn{1}{c|}{ Fecha } & \multicolumn{1}{c}{ Acontecimiento } \\
9 diciembre & $\begin{array}{l}\text { La Guardia Civil detiene a 14 personas (incluida Marta Domínguez, el doctor } \\
\text { Fuentes -también involucrado en otra operación contra el dopaje en 2006, la } \\
\text { Operación Puerto- y Pascua (uno de los entrenadores de atletismo de mayor } \\
\text { éxito en España) bajo los cargos de delito contra la salud pública y tráfico de } \\
\text { sustancias dopantes. Todos ellos deben comparecer en el juzgado durante las } \\
\text { siguientes semanas. }\end{array}$ \\
\hline \hline 10 diciembre & $\begin{array}{l}\text { Domínguez es suspendida de forma preventiva como vicepresidenta de la Real } \\
\text { Federación Española de Atletismo (RFEA). }\end{array}$ \\
\hline \hline 30 diciembre & $\begin{array}{l}\text { Domínguez comparece ante la juez que instruye el caso y es acusada } \\
\text { formalmente de los cargos de delito contra la salud pública (venta y suministro } \\
\text { de sustancias dopantes) y blanqueo de dinero. Ella niega todos los cargos. }\end{array}$ \\
\hline \hline 28 enero & $\begin{array}{l}\text { La juez divide la causa en cuatro ramas diferentes. Una de ellas concierne de } \\
\text { manera específica a Domínguez y otros deportistas. }\end{array}$ \\
\hline \hline 14 abril & $\begin{array}{l}\text { La juez archiva provisionalmente la imputación a Domínguez por el delito de } \\
\text { tráfico de sustancias dopantes aunque se mantienen otros dos cargos. }\end{array}$ \\
\hline \hline 12 mayo & $\begin{array}{l}\text { La juez anula las escuchas ordenadas a Domínguez durante la Operación Galgo. } \\
\text { La fiscalía recurre esta decisión. }\end{array}$ \\
\hline \hline 29 septiembre & $\begin{array}{l}\text { Domínguez es exculpada de los cargos de venta ilegal de sustancias y suministro } \\
\text { de fármacos sin receta médica. }\end{array}$ \\
\hline \hline & $\begin{array}{l}\text { Sobreseimiento de la causa contra Domínguez y otros dos acusados por el delito } \\
\text { de dopaje deportivo. Su entrenador (César Pérez) sigue imputado por haber } \\
\text { todavía indicios de que presuntamente dopaba a su pupila. }\end{array}$ \\
\hline \hline
\end{tabular}




\begin{tabular}{c|l}
\hline \hline 30 octubre & $\begin{array}{l}\text { Después de } 15 \text { meses, Domínguez vuelve a la competición y gana una carrera } \\
\text { popular en Madrid }\end{array}$ \\
\hline \hline 17 noviembre & $\begin{array}{l}\text { Domínguez es absuelta de la acusación de delito fiscal, el último cargo } \\
\text { relacionado con la Operación Galgo. Esta información se publica el 23 de } \\
\text { noviembre. }\end{array}$ \\
\hline \hline 20 noviembre & Domínguez es elegida senadora por el Partido Popular en su provincia natal. \\
\hline \hline $\mathbf{2 0 1 2}$ & $\begin{array}{l}\text { La Audiencia Provincial de Madrid declara la nulidad de todas las pruebas } \\
\text { incriminatorias presentadas lo que conlleva la absolución del resto de implicados } \\
\text { en la Operación Galgo. }\end{array}$ \\
\hline
\end{tabular}

Fuente: elaboración propia a partir de la información publicada en El Mundo y en El País.

\section{Metodología}

\subsection{Selección de los periódicos}

En primer lugar hay que señalar que se utilizaron para este estudio periódicos denominados como de "influencia dominante" ya que como señala Imbert (1982: 143): "Estos periódicos juegan así, en los diferentes países, un rol determinante en el condicionamiento de la opinión pública", por encima del que puede jugar la televisión ya que aunque ésta pueda influir en los comportamientos cotidianos, es la prensa la que fija los contenidos ideológicos.

De esta forma, los periódicos elegidos para el análisis fueron los diarios de información general El Mundo y El País, ya que son los que mayor difusión tienen en España dentro su categoría. Concretamente se revisó la edición de Madrid. El hecho de escoger periódicos generalistas y no prensa deportiva especializada se debe al mayor impacto que estos diarios tienen en la población en general ya que cuando un caso de dopaje es reflejado en ellos, se denota su mayor gravedad ya que tiene que "competir" con otro tipo de noticias que no son estrictamente deportivas.

El Mundo tuvo un promedio de tirada de 344.581 ejemplares en 20112. Su cabecera apareció por primera vez el 23 de octubre de 1989, después de la salida como director de Diario 16 de Pedro J. Ramírez. Este periódico define su línea editorial como liberal, con posiciones próximas a la derecha.

El País es el periódico más vendido en España, con un promedio de tirada de $461.788^{3}$ ejemplares en 2011. Este periódico fue publicado por primera vez el 4 de mayo de 1976, seis meses después de la muerte de Franco, al comienzo de la transición española a la democracia. La ideología del periódico se ha caracterizado siempre por una inclinación hacia el europeísmo. Políticamente es considerado como un periódico moderado de izquierda.

Se revisaron un total de 298 ejemplares de estos periódicos (149 de cada cabecera) desde el 1 de octubre 2010 (fecha en la que se hizo público el dopaje de contador en el Tour de Francia) hasta el 28 de febrero 2011, dos semanas después de la absolución de Contador por parte de la RFEC ${ }^{4}$. Durante el análisis de estos cinco meses se puede explicar cómo estos casos fueron tratados por ambos periódicos, aun 
sabiendo a día de hoy cómo terminaron, tal y como se expuso en la sección anterior. Además, otra razón para la elección de estas fechas se debe a que a finales de febrero 2011 comenzaron a aparecer en prensa las primeras noticias de Contador relacionadas con asuntos estrictamente deportivos 5 ; hasta ese momento, la práctica totalidad de las noticias que concernían a estos dos deportistas estaban relacionadas con temas de dopaje, excepto 15 (4 en El País y 11 en El Mundo) que no se incluyeron en el análisis final.

\subsection{Recogida y análisis de la información}

Dado que el objetivo de este trabajo es analizar la cobertura realizada de los casos Contador y Domínguez en dos periódicos distintos, la combinación de técnicas cuantitativas y cualitativas parece la más conveniente. Las técnicas cuantitativas han sido ampliamente utilizadas en investigaciones relacionadas con los medios de comunicación (Casetti y di Chio, 1999; Irgatua, 2006). En el caso que nos ocupa, se utilizaron las versiones digitalizadas con OCR del periódico El País y la versión impresa que aparece en la plataforma Orbyt para El Mundo. Concretamente se utilizaron los términos dop*6, Contador y Galgo, para de esta forma recoger todas las noticias en las que aparecía el dopaje de forma directa o indirecta (independientemente del deportista), además de todas aquellas en las que estos dos deportistas no estaban relacionados directamente con el dopaje y su temática era estrictamente deportiva ${ }^{7}$. Todas las noticias recogidas se incluyeron en una base de datos elaborada en el programa FileMaker Pro versión 12 utilizando los siguientes campos para su clasificación:

Fecha de publicación en el periódico.

Ubicación: lugar donde se publicó la noticia (primera página o en el interior del periódico).

Tipo de artículo: artículos generales, artículos de opinión, cartas al director, editoriales y otros.

Tema: si la noticia incluía información de Contador, Domínguez, la Operación Galgo (cuando no se hacía referencia a Domínguez) o de información general sobre el dopaje relacionada con otros casos.

Sin embargo, este método de investigación tiene importantes limitaciones, ya que no captura el contexto y reduce los datos obtenidos a números y porcentajes (Manning y Cullum Swan-, 1998). Por esa razón, siguiendo las indicaciones de Duncan (1993), se realizó un estudio interpretativo (cualitativo) para proporcionar un análisis más completo de la noticia. A través de este método, podemos tener una mayor comprensión de los textos y realizar una mejor comparación entre las diferentes variables analizadas para interpretar los resultados de manera más completa. Sin embargo, como señala Duncan (1993: 27), este método tiene sus limitaciones: "el investigador nunca puede estar absolutamente seguro de cómo un individuo en particular puede percibir un texto dado, porque el significado se crea en la interacción 
entre el texto y el lector".

\section{Resultados}

\subsection{Cuantitativos}

Entre los dos periódicos se recogieron un total de 555 noticias relacionadas con el dopaje durante los 5 meses de análisis, siendo el diario El Mundo el que mayor difusión dio a esta temática (314 noticias frente a 241 en El País). En cuanto al número de noticias aparecidas en portada, El Mundo incluyó 19 y El País, 24 (Tabla $3)$.

Tabla 3. Aparición de noticias relacionadas con el dopaje en portada.

\begin{tabular}{lccc} 
Temática & El Mundo & El Pais & Total \\
\hline Caso Contador & $9(47,37 \%)$ & $11(45,83 \%)$ & 20 \\
Caso Domínguez & $7(36,84 \%)$ & $9(37,5 \%)$ & 16 \\
Operación Galgo & $3(15,79 \%)$ & $4(16,67 \%)$ & 7 \\
\hline Total & $19(100 \%)$ & $24(100 \%)$ & 43
\end{tabular}

Resulta necesario señalar que, aunque estos datos parecen equilibrados, la duración del caso Contador fue mayor que la del caso Domínguez (concretamente apareció en prensa 70 días antes), con lo que el impacto mediático de la implicación de Domínguez en la Operación Galgo fue mayor en ambos periódicos. Los datos recogidos del análisis de las noticias aparecidas en el interior de cada diario confirman esta tendencia (Tabla 4).

Tabla 4. Aparición de noticias relacionadas con el dopaje en el interior.

\begin{tabular}{|c|c|c|c|}
\hline Temática & El Mundo & El Pais & Total \\
\hline Caso Contador & $116(39,32 \%)$ & $75(34,56 \%)$ & 191 \\
\hline Caso Domínguez & $80(27,12 \%)$ & $55(25,35 \%)$ & 135 \\
\hline Casos Contador y Domínguez ${ }^{8}$ & $11(3,73 \%)$ & $4(1,84 \%)$ & 15 \\
\hline Operación Galgo & $46(15,59 \%)$ & $32(14,75 \%)$ & 78 \\
\hline Otros & $42(14,24 \%)$ & $51(23,5 \%)$ & 93 \\
\hline Total & 295 & 217 & 512 \\
\hline
\end{tabular}

Aunque se constata que la distribución temática es similar en base a la cobertura 
que realiza cada periódico, podemos observar ciertas diferencias tanto en su distribución temporal. La gráfica 1 muestra que durante los tres primeros meses la distribución de noticias fue pareja aunque ligeramente inferior en el caso de El País. Sin embargo, esta tendencia se rompe a partir del mes de enero en donde las noticias aparecidas en El Mundo empiezan a aumentar significativamente llegando casi a duplicar las que aparecen en el otro diario durante el mes de febrero (80 noticias en El Mundo por 42 noticias en El País). En estas noticias se presta mucha mayor atención al caso Contador (57 noticias frente a 21 en El País durante el mes de febrero), siendo el caso Domínguez el que progresivamente va perdiendo presencia en El País ( 16 noticias en enero y 3 en febrero) aunque sigue recibiendo una mayor cobertura informativa en El Mundo (28 noticias en enero y 7 en febrero).

Gráfica 1. Distribución temporal de las noticias según temática.

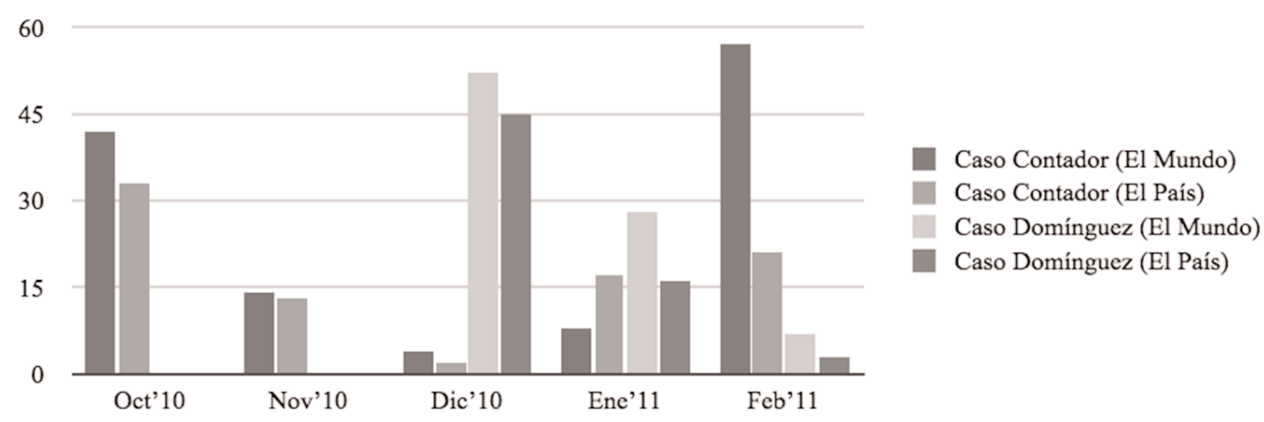

Por último, la gráfica 2 muestra los datos relacionados con la tipología del artículo. Puede observarse cómo la mayoría de las noticias conciernen al caso Contador, concretamente 144 son artículos de carácter general (75 en El Mundo por 69 en El País), seguido de 21 artículos de opinión (13 en El Mundo por 8 en El País), 13 cartas al director (9 en El Mundo por 4 en El País), 9 editoriales (8 en El Mundo por 1 en El País) y 39 artículos clasificados en la sección de 'otros' (31 en El Mundo por 8 en El País). En el caso Domínguez, los artículos generales son 123 (66 en El Mundo por 57 en El País), 9 artículos de opinión (todos ellos publicados en $\mathrm{El}$ Mundo), 2 cartas al director ( 2 en El Mundo por 1 en El País), 7 editoriales (6 en El Mundo por 1 en El País) y 24 artículos en la sección de 'otros' (15 en El Mundo por 9 en El País). 
Gráfica 2. Distribución las noticias en función de su tipología9

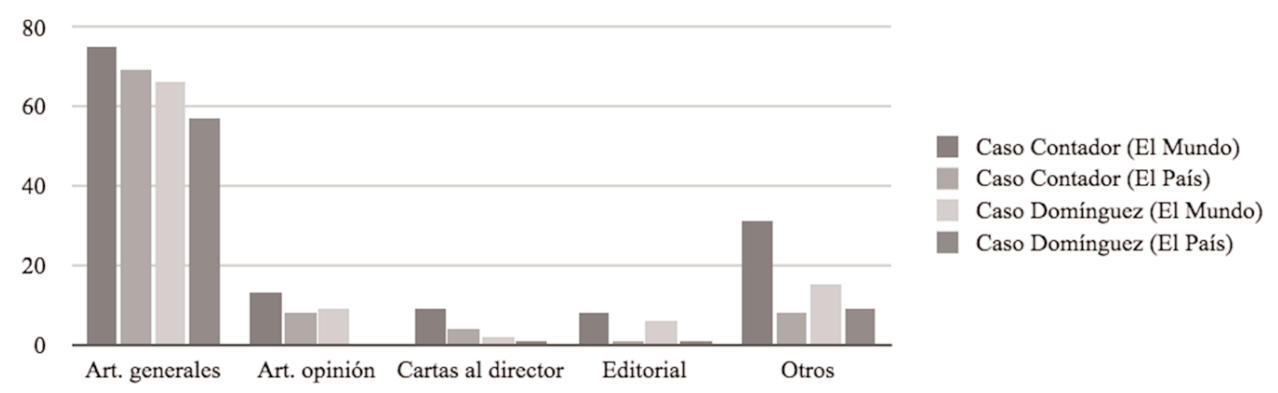

Las grandes diferencias encontradas entre los dos periódicos en cuanto al tratamiento de ambos casos en las editoriales y en los artículos de opinión serán reflejadas en el siguiente apartado ya que se mostrará cómo el contenido de dichos artículos contribuyó a representar una imagen diferente de estos deportistas, principalmente en el caso Domínguez.

\subsection{Cualitativos}

Una vez realizado el análisis de contenido de los artículos recogidos, se han destacado cinco categorías principales: economía, política, presunción de inocencia, privacidad y nacionalismo deportivo. A continuación se discutirán cada una de estas categorías.

\subsubsection{Aspectos económicos}

Mientras que en el caso de Contador no hay prácticamente referencias a cuestiones económicas, tres días después de que se hiciera público el caso Domínguez (12-12-2010), aparece un titular en la portada de El País que dice: "El dinero traicionó a Marta Domínguez". Además, dentro de esta edición se puede leer: "Según fuentes de la investigación hay cuentas corrientes en paraísos fiscales e indicios de blanqueo de dinero. Es la pista del dinero, el móvil económico que llevan consigo muchos delitos" (p. 1). Además, las cuestiones económicas siguen apareciendo en la edición siguiente. Por ejemplo, ambos periódicos refuerzan la idea de que Domínguez recibe una gran cantidad de dinero por su condición de atleta profesional no sólo por su patrocinio sino también dinero del gobierno, de la federación y de otras instituciones públicas (El Mundo, 12-12-2010, p. 44; El Mundo, 14-12-2010, p. 41; El País, 15-12-2010, p. 56), idea que también aparece en un artículo de El Mundo titulado "«El motivo es el dinero, ella corre por dinero»" (11-12-2010, p. 45), en donde se recogen las declaraciones del que fue entrenador de Domínguez durante 24 años y que añade: "La atleta palentina es «muy ambiciosa» y el dinero también atrae su atención”. Todas estas informaciones contribuyen a construir una imagen muy 
negativa de la corredora ya que son dichas por alguien que ha pertenecido a su entorno más cercano durante mucho tiempo. De hecho, las declaraciones que hizo el exentrenador de Domínguez ante la Guardia Civil fueron determinantes para impulsar la Operación Galgo (El Mundo, 24-01-2011, p. 10 DXT).

Por el contrario, Contador parece no ser tocado por temas financieros, pues aunque una posible sanción conllevaría también una multa económica, la única referencia directa a estos temas es la entrevista con el gerente de Saxo Bank (Lars Christensen), la empresa que patrocina el equipo de Contador. Durante la entrevista, el Sr. Christensen señala que hoy en día el ciclismo tiene un alto riesgo para el patrocinio y si Contador es finalmente suspendido: "el caso invitará a la reflexión de muchos patrocinadores que se preguntarán si en este deporte estamos en una lotería y no se puede planificar" (El País, 28-10-2010, p. 53).

\subsubsection{Aspectos políticos}

El enfoque político de ambos casos es diferente. El caso Contador adquiere una dimensión más internacional (en donde se presenta a un exitoso deportista español que es atacado injustamente por organizaciones como la UCI y la AMA), y el caso Domínguez se aborda en mayor medida como algo nacional nacional al estar inmersa la justicia y las fuerzas y cuerpos de seguridad del Estado.

En el caso de Contador la siguiente cita ilustra esta idea:

(...) su problema [en referencia a Contador] es fruto de las peleas políticas incesantes entre la Agencia Mundial Antidopaje (AMA) y la UCI, por un lado, y las autoridades españolas, por otro (...) La UCI siempre ha acusado al ciclismo español de ser excesivamente complaciente con sus dopados (El País, 10-11-2010, p. 55).

Bajo estas acusaciones de la UCI, diferentes autoridades políticas españolas como el Secretario de Estado para el Deporte (Jaime Lissavetzky), la Agencia Estatal Antidopaje y el Consejo Superior de Deportes defendieron la política antidopaje que se está llevando a cabo declarando que "España no tiene un problema especial con el dopaje" (El País, 17-11-2010, p. 47), o que España está situada "en la vanguardia de la lucha contra el dopaje" (El País, 20-10-2010, p. 50; El Mundo, 12-12-2010, p. 43). Sin embargo, las propias declaraciones de Lissavetzky en el Foro Ferrándiz-AS denotan una preocupación por la imagen internacional que se da de España: "no hay un problema «mayor ni menor que en el resto del mundo» con el dopaje, aunque reconoció que la presunta implicación de deportistas de primer nivel afecta a la imagen" (El Mundo, 08-10-2012, p. 50). También, desde la Asociación de Deportistas Profesionales se acusa a la AMA diciendo que: "El AMA se creó a instancias de los gobiernos, pero ahora parece que está por encima del bien y del mal. Nosotros no tenemos ni voz ni voto y nos ven como los malos de la película" ( $E l$ Mundo, 28-12-2010, p. 36), señalando que efectivamente dentro de este organismo internacional los deportistas no tienen representación.

De esta forma, Contador recibe el apoyo de numerosas figuras públicas que salen en su defensa, entre ellas destacan el presidente del Comité Olímpico Español 
(COE), Alejandro Blanco (El País, 28-10-2010, p. 53; El Mundo, 29-10-2010, p. 47 y El País, 17-11-2010, p. 47), portavoces de los principales partidos políticos, PP y PSOE (El Mundo, 10-02-2011, portada), Mariano Rajoy (El Mundo, 14-02-2011, p. 13 DXT) e incluso el presidente del Gobierno, José Luis Rodríguez Zapatero, quien a través de Twitter declaró: "No hay ninguna razón jurídica para sancionar a Contador" (portada en ambos periódicos el 11-02-2011). Estos apoyos fueron alabados en diferentes editoriales y artículos de opinión de El Mundo mientras que en El País no tuvieron tanto eco ya que ni si quiera se recogieron algunos de ellos (como fue el caso del dado por Rajoy o los portavoces políticos).

Esta diferencia de tratamiento se agudiza en el caso Domínguez, principalmente en la manera de relacionar la Operación Galgo con el Ministro del Interior socialista. Por ejemplo, en El Mundo aparece toda una página en la que se puede leer: "Cuando Rubalcaba era entrenado por Pascua. El vicepresidente y responsable de Interior, campeón de España universitario de 100 en 1975, fue dirigido por el técnico detenido" (11-12-2010, p. 43). Dos días después, siguiendo esta tónica pero cargando más el mensaje, puede leerse en una de las columnas de opinión de este diario: "Lo fascinante sería investigar si Rubalcaba ganó dopado aquel campeonato de España y si su marca de 10.9 segundos estuvo adulterada por la química del afán de ganar y subir al podio, vulgo cajón, a cualquier precio" (El Mundo, 13-12-2010, p. 2). Esta situación llegó a su punto culminante cuando el vicesecretario de Comunicación del PP acusó a Rubalcaba de lanzar esta operación policial "muy mediática" dos horas después de la comparecencia del presidente Zapatero sobre el conflicto de los controladores aéreos para así desviar la atención pública sobre este asunto (El País, 13-12-2010, p. 19; El Mundo, 13-12-2010, p. 10 DXT).

Por último, la afiliación política de la atleta (que fue concejal en Palencia por el PP en 2003 y actualmente es senadora por el mismo partido desde 2011) también fue un tema que apareció reflejado aunque únicamente en El Mundo. Concretamente, durante la primera entrevista que dio Domínguez (El Mundo, 26-01-2010) se destacaron algunos puntos relacionados con esta afiliación política declarando que "mi tendencia política me ha perjudicado" (en portada). Además, señaló el trato diferente que había recibido en comparación con Contador: "Contador ha dado positivo y la gente le ha apoyado. No quiero comparar los casos, pero la gente no ha respondido igual. España no se ha portado bien conmigo" (p. 38).

\subsubsection{Presunción de inocencia}

En este apartado se mostrará cómo, durante el periodo analizado, ambos periódicos mantuvieron la presunción de inocencia para Contador mientras que no fue así para Domínguez.

En primer lugar, el día en el que se hizo público en prensa la Operación Galgo, podemos leer los siguientes titulares:

“iDe reina del estadio a camello del dopaje?" o "La 'traición' de la novia de España” (El Mundo, 10-12-2010, portada y p. 43). 
"El dopaje también acaba con la gran dama del atletismo español" o "El dopaje derriba otro mito" (El Pais, 10-12-2010, portada y p. 62).

No obstante, cuando salió a la luz el positivo de Contador, la portada de estos periódicos lo reflejó de manera diferente:

“El dopaje del solomillo de Irún. Destacados expertos avalan la tesis de la 'contaminación alimentaria' de Contador" (El Mundo, 01-10-2010, portada).

"Jaque al ciclismo por el positivo de Contador. El tricampeón del Tour atribuye a una 'contaminación alimentaria' el hallazgo de clembuterol en su orina. El corredor, que se enfrenta a dos años de sanción, sostiene que se debió a una carne procedente de Irún” (El País, 01-10-2010, portada).

El Mundo, en su editorial de ese mismo día señala que: "es muy probable que Contador esté diciendo la verdad (...) De momento, hay que concederle el beneficio de la duda" (01-10-2010, p. 3). Incluso cuando se conoce la primera propuesta de sanción de la RFEC, voces relevantes en materia jurídica como la del presidente de la Audiencia Nacional la critican diciendo que "a Contador no se le respeta la presunción de inocencia” (El Mundo, 13-02-2011, p. 43).

En el caso de Domínguez, ya desde un principio el presidente de la RFEA, José María Odriozola, suspendió provisionalmente a la atleta como vicepresidenta de la RFEA (El País, 11-12-2010, p. 55), sin asumir la presunción de inocencia del atleta. Además, la prensa llega a poner en tela de juicio sus últimas actuaciones deportivas. A pesar de que nunca ha dado positivo por dopaje en toda su carrera, no es razón para hablar de su "conducta intachable", como sí se hace con Contador (El País, 11-102010, p. 55), sino que se sugiere cómo los métodos de dopaje pueden eludir los controles:

Su seguridad exterior y su gran consideración social, sin embargo, no significaban que en la federación española, de la que era vicepresidenta hasta ayer, no pensaran que había algo sospechoso en su relación ultima con César Pérez y en su modo guadianesco de llegar a las grandes citas, con escasa competición previa y con mínimas salidas a correr al extranjero. Por ello la sometieron, solo por cuenta de la federación española, a 32 controles fuera de competición en los dos últimos años, a los que debería sumarse los ordenados por la IAAF ${ }^{10}$ y la AMA. En todos ellos, el resultado fue negativo, lo que también habla de la sofisticación con que se puede combinar autotransfusiones con microdosis de EPO ${ }^{11}$ para no dejar rastro" (El País, 11-12-2010, p. 53).

También se pueden leer duras acusaciones en diferentes columnas de opinión: "(...) me pregunto cómo estas atletas, que lo tenían todo pudieron caer tan bajo" (El Mundo, 11-12-2010, p. 2); "Marta era campeona y ejemplo, y hablamos en pasado, porque, suceda lo que suceda, ya no representará ambas cosas" (El Mundo, 10-122010, p. 2).

El propio lenguaje de alguna de las crónicas muestra a Domínguez más como una criminal que como una deportista. Por ejemplo, se refieren a ella como "la mujer más buscada de España” en dos ocasiones (El Mundo, 21-12-2010, p. 49 y 23-12-2010, 
p. 52), o de manera más explícita se relata cómo fue su primera declaración ante la policía:

«No estaba acostumbrada a la presión que supone declarar ante unos agentes de seguridad y se hundió anímicamente, por eso fue necesario que su interrogatorio se hiciera ante la presencia de un psicólogo». Marta Domínguez, en avanzado estado de gestación, se desplomó en la mañana del pasado jueves, cuando especialistas de la Guardia Civil la acorralaron por su implicación en la Operación Galgo. Fuentes relacionadas con la investigación aseguran que la atleta apenas opuso resistencia a las miembros de la UCO ${ }^{12}$ " (El Mundo, 12-12-2010, p. 43).

Hay que rebuscar en el interior de las crónicas para encontrar las referencias a la presunción de inocencia, como la que aparece en El Mundo: "En defensa de la atleta hay que mencionar la presunción de inocencia y el hecho de que jamás ha dado positivo en un control antidopaje, pero las acusaciones que se vierten sobre ella son más graves que el consumo" (12-12-2010, p. 44), aunque en esa misma crónica se utiliza la expresión "tonillo corporativista" al referirse a unas declaraciones que hizo a $E l$ Pais durante una entrevista en 2009 en donde se posicionaba en contra de estigmatizar a los deportistas que habían tenido un positivo por dopaje durante su carrera. Otro ejemplo son las declaraciones realizadas por Alejandro Blanco (presidente del COE), ya que parece que según lo publicado en El País no da su apoyo a la atleta tal y como había hecho anteriormente con Contador: "Estoy dolido, sorprendido e impactado, por la categoría de Marta" (El País, 11-12-2010, p. 57). Por el contrario, en El Mundo, si bien se recogen estas mismas declaraciones (11-12-2010, p. 44), una página después se añade que: "El mandatario quiso dejar intacta la presunción de inocencia de la atleta palentina: «Dejemos que se sepa la verdad para hacer una valoración. El mal momento ya lo estamos pasado», afirma" (p. 45). Por lo que se puede apreciar cierto sesgo informativo al respecto. En una entrevista posterior, Blanco mantiene esa postura al afirmar: "todos los deportistas son inocentes hasta que se demuestre lo contrario. La presunción de inocencia tiene que ser prioritaria" ( $E l$ Mundo, 30-01-2011, p. 43).

Sin embargo, a partir de la publicación en El Mundo de un artículo titulado: “Trampa para un galgo ¿mal criado?” (04-01-2011, p. 38), se produce progresivamente un cambio de postura en este periódico. En dicho artículo se expone el informe inicial de la policía y se pone en tela de juicio la investigación realizada por la Guardia Civil ya que, según este diario, se fundamenta en pruebas poco consistentes afirmando que: "Esta aparente inconsistencia de las primeras pesquisas fundamentaría la petición de nulidad, intento de frenar a un galgo que hasta ahora parecía imparable". A este artículo le siguieron posteriormente otros en la misma línea en donde se seguía insistiendo en la inconsistencia de la investigación ( $E l$ Mundo, 05-01-2011, p. 40), información que no es recogida en El País. A partir de esta fecha, la información que aparece en El Mundo relacionada con la Operación Galgo empieza a dejar de incluir el nombre de Domínguez y pasa a centrarse en otros imputados, principalmente en el médico Eufemiano Fuentes. El punto determinante en este cambio de postura en el periódico es la publicación de un editorial con el 
título "Marta Domínguez es inocente hasta que no se demuestre lo contrario" (26-012011) en el que puede leerse:

Hemos escuchado insinuaciones sobre las personas con las que se relaciona y las especulaciones de su antiguo entrenador, pero nadie ha aportado un testimonio fidedigno sobre alguna conducta reprochable de esta atleta. Ella merece todo el respeto y toda la credibilidad hasta que este asunto quede sustanciado judicialmente" (p. 3).

En los días siguientes se suceden varios artículos de opinión en los que se leen alegatos a favor de Domínguez e incluso en contra de la actuación de la Guardia Civil, algo inédito en los periódicos analizados hasta la fecha:

Lo que se ha hecho contra Marta Domínguez ha sido un atentado civil. Sin balas ni metralla, pero un atentado, un intento de eliminarla con suposiciones que parecen de aficionados más que de un cuerpo de policía respetable (El Mundo, 27-01-2011, p. 41).

Marta Domínguez comienza a intuir que puede triunfar en la carrera más difícil de su vida: la recuperación de credibilidad ante la opinión pública. Una dura competición para defender la inocencia de las acusaciones de consumo de tráfico de sustancias dopantes y de delito fiscal (El Mundo, 28-01-2011, p. 44).

¿Por qué tratamos a nuestros pocos grandes campeones mucho peor que a nuestros políticos a granel? La presunción de inocencia rige para Camps o Chaves, pero no para Alberto Contador o Marta Domínguez. La corrupción es a la política lo que el doping al deporte (El Mundo, 13-02-2011, p. 2).

\subsubsection{Privacidad}

El tema de la privacidad se refiere principalmente al caso Domínguez, porque en las noticias sobre Contador no se encontró ninguna información relevante de carácter personal. Sin embargo, en las noticias (y fotos) que tratan sobre Domínguez se puede encontrar información privada que muestra el diferente tratamiento que recibió en estos medios. A continuación se enumeran algunos ejemplos:

$\mathrm{Su}$ domicilio personal aparece publicado en ambos periódicos llegando incluso a aparecer fotografías de la fachada de su casa (El Mundo, 12-12-2010, p. 44; El País, 10-12-2010, p. 63 y El País, 11-12-2010, pp. 54-55).

$\mathrm{Su}$ familia también aparece reflejada de diferente manera: su madre está preocupada por su hija porque está embarazada (El Mundo, 12-12-2010, p. 44; El País, 10-122010, p. 63.); su hermana aparece fotografiada entrando al domicilio de Marta (El País, 12-12-2010, p. 48); otra imagen muestra a la atleta yendo al juzgado junto con su marido y su abogado (El País, 09-01-2011, p. 50), dando incluso sus nombres completos.

Se da información personal extradeportiva como por ejemplo que quiso ser policía pero que "no dio la talla" (El Mundo, 12-12-2010, p. 44), o que es miembro de una hermandad religiosa y reza antes de cada competición (El Mundo, 12-12-2010, p. 45; 
El País, 11-12-2010, p. 54).

Incluso el hecho de estar embarazada supone un gravamen a su condición de imputada: "En un dulce ocaso, decidió ser madre, por lo que su implicación parece más gravosa y torpe" (El Mundo, 10-12-2010, p. 46).

Sin embargo, de acuerdo con la información publicada en ambos periódicos, no sabemos nada acerca de la vida personal de Contador a excepción del nombre propio de su madre y su novia (aparecidos en un artículo de El Mundo, 10-02-2011, p. 35) y que reside en Pinto (ciudad cercana a Madrid).

\subsubsection{Nacionalismo deportivo}

2010 fue un año de gran éxito para el deporte español ${ }^{13}$. El propio diario $E l$ Mundo señaló que "Al margen de la crisis. El deporte ha sido prácticamente la única actividad que ha reportado satisfacciones en 2010" (31-12-2010, p. 41), de hecho, uno de sus columnistas, bajo el título "Que viva España", señala:

Esa sensación única, de tribu, que nos hace sentir la selección española de fútbol, o la de baloncesto, o a Rafa Nadal y los chicos de la Davis, o a Gasol en sus Lakers, o a Contador sin filete de clembuterol, o a Lorenzo, Pedrosa y los kamikaces de la moto, o a Alonso, que va más deprisa que su coche. Entonces nuestra bandera y nuestro himno nos llevan a una historia común, a una alegría compartida, a un sentimiento que nos une sin mirar la procedencia (16-10-2010, p. 56).

Cuando en diciembre se hizo pública la Operación Galgo la imagen de España quedó empañada ya que se la relacionaba como un "paraíso para el dopaje". En este sentido, el único editorial publicado por El País sobre temas relacionados con el dopaje apareció el 11 de diciembre 2010 y alertaba sobre lo peligroso que puede ser para los intereses españoles la permisividad con estas prácticas. En concreto, decía lo siguiente:

Es esencial que la justicia indague y esclarezca los casos que empañan el deporte español (...). Pero lo verdaderamente crucial es que se haga justicia y que nadie en el mundo de la competición pueda decir en el futuro que en España existen dos varas de medir. Una para el prójimo en el extranjero, y otra de puertas adentro" (p. 30).

En esta misma edición también se mencionaron los titulares de otros periódicos extranjeros como La Gazzetta dello Sport (Italia), Le Monde (Francia), Daily Mail (Reino Unido) y Récord (Portugal) con el fin de mostrar cómo la opinión internacional ha recibido la noticia de la Operación Galgo y la imputación de Domínguez (El País, 11-12-2010, p. 57). Sin embargo, este periódico no reflejó el impacto de la noticia de Contador en la prensa internacional, algo que El Mundo sí recogió en una de sus columnas de opinión bajo el título "Contador y 'L'Equipe' del rencor" en el que se podía leer lo siguiente:

Sin campañas como las de L'Equipe o la del sensacionalista alemán Bild, que ha 
sacado en portada un montaje con Contador y una jeringuilla, los leves rastros de sustancias prohibidas no tendrían su devastador eco en la fama del ciclismo y de los ciclistas. Sobre todo si son españoles" (02-10-2010, p. 23).

Esto muestra la manera en que ambos periódicos abordaron la noticia del positivo de Contador, en donde se culpa a las instituciones internacionales (AMA y UCI), la prensa extranjera e incluso a la calidad de la carne francesa del positivo de Contador:

(...) la noche del 20, su amigo y socio como organizador de la Vuelta a Castilla y León, José Luis López Cerrón, había llegado de visita al hotel de Pau en el que estaba alojado el Astana portando un rico solomillo que el cocinero del equipo, Paco Olaya, harto de la mala carne de los hoteles de Francia, le había pedido (El País, 01-10-2010, p. 58).

Declaraciones que también recoge El Mundo (01-10-2010, p. 44-45). Por lo tanto, según la versión recogida en la prensa, la carne traída de España, además de "deliciosa" parecía tener una ínfima cantidad de clembuterol que originó el positivo por dopaje, dando a entender que no era posible que Contador hubiera utilizado sustancias dopantes. Solamente encontramos un artículo en El Mundo del mismo día 1 de octubre 2010 (p. 47) en donde se recogen algunas incongruencias de la versión de Contador bajo el epígrafe: "Las lagunas de Contador. Sobredosis de cualidades. La versión del español encadena hechos extraños y aspectos ilógicos". Sin embargo, de ahí en adelante no se vuelven a plantear dudas sobre el testimonio del ciclista y se refuerza la idea de que hay intereses internacionales para culpar a España de su permisividad con el dopaje aún más cuando la RFEC exoneró a Contador, algo que refleja el siguiente editorial de El Mundo:

Diversas personalidades deportivas de Francia, Alemania, Italia, EEUU y otros países criticaron ayer la absolución de Alberto Contador por parte del Comité de Competición de la Federación Española de Ciclismo. El ex ciclista y entrenador Cyrille Guimard afirmó que «la cultura del dopaje sigue muy arraigada en España». La afirmación de Guimard refleja la confusión creada en torno a este caso, en el que se ha querido ver en la decisión de no sancionar a Contador una muestra de una hipotética permisividad de las autoridades deportivas españolas con la práctica del dopaje en favor de un campeón nacional (17-02-2011, p. 3).

Por su parte, el presidente de la UCI criticó el apoyo dado a Contador por parte de diferentes personalidades políticas y afirmó: "Estoy decepcionado. Esa presión ha sido injustificada. No ayuda a la imagen de España" (El Mundo, 17-02-2011, p. 41). Todo lo contrario que el presidente del COE que declaró: "Aplaudo públicamente al presidente del Gobierno y al líder de la oposición por apoyar a los deportistas, que son nuestros mejores embajadores" (El Mundo, 16-02-2011, p. 41). El propio Contador afirmó durante una entrevistas que estaba "muy agradecido, pero lo que han hecho es una cuestión de justicia, no de patriotismo. No hay que malinterpretarlo" (El Mundo, 16-02-2011, p. 39). 
En este sentido, en relación con el caso Contador, se percibe en El Mundo una mayor presencia de esta línea argumental ya que en El País se incluyen artículos en donde se cuestiona el problema del dopaje desde otra perspectiva:

(...) la política emprendida en la lucha contra el dopaje exige de nuevos impulsos en lo jurídico y en lo ético para evitar que se instale en la opinión pública, especialmente en la internacional, la idea de que los resultados del deporte español no puede disociarse de los problemas de dopaje (El País, 12-12-2010, p. 48).

\section{Conclusiones}

Los periódicos tienen un enorme impacto en la opinión pública y los casos Contador y Domínguez no son una excepción. Si hablamos de dopaje, parece que no hay posiciones intermedias y los deportistas que se ven involucrados en estos casos sólo pueden desempeñar dos papeles: héroes o villanos (Mondenard, 2003). En los casos analizados, Contador se presenta como un deportista honesto que se ve envuelto en un caso de dopaje "por accidente". Por el contrario, Domínguez interpreta el papel de culpable incluso antes de ser formalmente condenada. En este sentido, la tendencia política de los periódicos analizados también parece influir en la manera de retratar a estos dos deportistas ya que en el caso de Domínguez se aprecia un tratamiento distinto por parte de El Mundo, que si bien empezó acusándola al igual que el otro diario, poco a poco fue suavizando su discurso hasta dejar evidente su presunción de inocencia aunque sin realizar ninguna autocrítica en relación a este cambio de línea editorial. Por su parte, en El País no se reflejó cambio alguno en las noticias sobre Domínguez, sino que se siguió insistiendo en presentar a esta atleta como culpable.

El punto en donde coinciden ambas cabeceras es el que concierne a la imagen internacional que un país puede dar si el éxito de sus deportistas queda bajo la sospecha del dopaje, tal y como ya ocurriera con la todavía abierta Operación Puerto (Soule y Lestrelin, 2011). Los políticos han utilizado el éxito de los deportistas españoles durante los últimos años como una manera de demostrar el poder del país (Brohm, 1993). Como declaró el presidente Zapatero durante la recepción a los campeones de la Copa Davis 2008: "Gracias a vuestros éxitos es fácil estar en el 'G8' del deporte. Estamos viviendo un momento óptimo y estamos entre los mejores países del mundo" (26-11-2008, El País). Sin embargo, si se centra la atención mediática sobre el dopaje como una guerra abierta de intereses internacionales en vez de abordar problemáticas más complejas, se está levantando una cortina de humo. Es necesario preguntarse si el dopaje no es consecuencia de una sociedad competitiva en donde hay que ser el mejor y en la que, por lo tanto, una conducta dopante podría considerarse como una práctica "normal" (Ehrenberg, 1991). Al deportista, como actor que refleja la sociedad en la que vive, se le demanda cada vez más (el propio lema olímpico así lo establece: "más rápido, más alto, más fuerte"), sin asumir realmente que existen unos límites. Como explican Guillon y Nicolet (2000: 32), el atleta es "el último eslabón de la cadena de ejecución, el más visible, quien consigue la 
victoria o la derrota, pero también el más vulnerable".

El futuro cambio de la actual ley antidopaje en España es un nuevo intento en esta dirección, sin embargo, el camino todavía es largo y no se logrará sólo con una nueva normativa. Es necesario plantear un debate más profundo sobre el deporte espectáculo, sus consecuencias y sus contradicciones, en el que se discuta la función (y responsabilidad) que juegan los medios de comunicación ya que resultan esenciales en la construcción del hecho deportivo.

\section{Bibliografía}

BROHM, J.-M. (1993). "20 tesis sobre el deporte". En Barbero, J. I. (Ed.), Materiales de sociología del deporte (Vol. 23). Madrid: La Piqueta. p. 47-55

CASETTI, F., \& DI CHIO, F. (1999). Análisis de la televisión. Instrumentos, métodos y prácticas de investigación. Barcelona: Paidós.

DOUGLAS, D. D. (2002). "To be young, gifted, black and female: A meditation on the cultural politics at play in representation of Venus and Serena Williams". En: Sociology of Sport Online, ${ }^{\circ} 5$, vol. 2.

DUNCAN, M. C. (1990). "Sports photographs and sexual difference: Images of women and men in the 1984 and 1988 Olympic Games". En: Sociology of Sport Journal, ${ }^{\circ}$ 7, p. 22-43.

(1993). "Beyond analyses of sport media texts: An argument for formal analyses of institutional structures". En: Sociology of Sport Journal, no 10, p. 353-372.

EHRENBERG, A. (1991). Le culte de la performance. Paris: Calmann-Lévy.

GUILLON, N., \& NICOLET, G. (2000). Le dopage. Paris: Flammarion.

HILLIARD, D. C. (2005). "Televised sport the (anti)sociological imagination". En EITZEN, D. S. (Ed.). Sport in contemporary society: An anthology ( $7^{\text {th }}$ ed.). Boulder: Paradigm. p. 77-86.

IGARTUA, J. J. (2006). Métodos cuantitativos de investigación en comunicación. Barcelona: Bosch.

IMBERT, G. (1982). "La presse d'influence dominante et la production du réel: à propos de "El País"”. En: Papers: Revista de Sociologia, no 18, p. 139-159.

MANNING, P. K., \& CULLUM-SWAN, B. (1998). "Narrative, content, and semiotic analysis". En DENZIN, N. K. \& LINCOLN, Y. S. (Eds.). Collecting and interpreting qualitative materials. Thousand Oaks: Sage. p. 246-273.

MESSNER, M. A., DUNBAR, M., \& HUNT, D. (2005). "The televised sport manhood formula". En EITZEN, D. S. (Ed.). Sport in contemporary society: An anthology $\left(7^{\text {th }}\right.$ ed.). Boulder: Paradigm. p. 98-111.

MONDENARD, J.-P. (2003). Dopage: l'imposture des performances. Paris: Chiron.

SOULE, B. \& LESTRELIN, L. (2011). "The Puerto Affair: Revealing the difficulties of the fight against doping". En: Journal of Sport and Social Issues, $\mathrm{n}^{\circ} 35$, vol. 2. p. 186208.

WALTON, T. (2001). "The Sprewell/Carlesimo episode: Unacceptable violence or unacceptable victim?". En: Sociology of Sport Journal, n 18. p. 345-357. 


\section{Notas}

1 Desde el 30 de julio 2010, cuando ganó la medalla de plata en los 3.000 m. obstáculos durante los Campeonatos de Europa, Domínguez no había regresado a la competición. Es necesario señalar que durante estos meses, además del proceso relacionado con la Operación Galgo, Domínguez estaba embarazada, dando a luz a su primer hijo el 22 de mayo 2011.

2 Información obtenida a través de la Oficina de Justificación de la Difusión. Disponible en: www.ojd.es, recuperada el 29-05-2012.

3 Ibid.

4 Es necesario señalar que la información relacionada con la Operación Galgo empezó a ser publicada el 10 de diciembre 2010.

5 La primera competición en la que participó Contador después de la absolución por parte de la Federación fue en la Vuelta al Algarve (Portugal), que comenzó el 16 de febrero 2011.

6 En la búsqueda se utilizó la raíz “dop” ya que así se incluían todas las conjugaciones del verbo "dopar" y la acepción inglesa doping que también se utiliza en ocasiones.

7 Ver si meto la noticia de Contador de participar en el Algarve o la de Marta en Madrid.

8 En 15 artículos (principalmente en artículos de opinión y editoriales) se encontraron referencias a ambos casos en el mismo texto.

9 Para la elaboración de esta gráfica se han tenido en cuenta las 15 noticias en donde aparecían nombrados ambos deportistas, contabilizándose doblemente. Por ejemplo, el único editorial sobre dopaje publicado en el El País aparece incluido en esta gráfica tanto en el caso Contador como en el caso Domínguez.

10 Siglas en inglés de la Federación Internacional de Atletismo (International Association of Athletics Federations).

11 Comúnmente se denomina así a la eritropoyetina, hormona de síntesis que aumenta la cantidad de glóbulos rojos y mejora el rendimiento muscular.

12 Unidad Central Operativa (UCO) de la Guardia Civil.

13 Entre los éxitos deportivos más importantes de ese año destacan los siguientes: la selección española ganó el Campeonato del Mundo en fútbol y el Campeonato Europeo de baloncesto, Rafael Nadal ganó los torneos de Roland Garros y Wimbledon en tenis, Jorge Lorenzo ganó el Campeonato del Mundo de motociclismo en la categoría MotoGP y Alberto Contador ganó el Tour de Francia en ciclismo. 


\section{Agradecimientos}

Este artículo se incluye dentro del proyecto de investigación financiado por la Agencia Mundial Antidopaje titulado: "Prévenir le dopage chez les jeunes sportifs en Espagne et en France: approche multidimensionnelle des processus de conduites dopantes" (2011-2013).

\section{Los autores}

Rodrigo Pardo es profesor en la Universidad Politécnica de Madrid y miembro del grupo de investigación Estudios Sociales y Humanistas en Actividad Física y Deporte. Sus temas de investigación se centran en el estudio del deporte como fenómeno social y la utilización del deporte como transmisor de valores.

Dominique Bodin es profesor en la Universidad de Rennes 2 donde asume la dirección del Laboratorio Violences, Identites, Politiques \& Sports (VIPS). Ha publicado numerosos libros y artículos relacionados principalmente con la violencia en el deporte en donde destaca Sports et Violences en Europe (2004). 